\title{
Are hippocampal lesions sufficient to cause lasting amnesia?
}

\author{
BRYAN T WOODS, ${ }^{*} \dagger$ WILLIAM SCHOENE, $\ddagger$ LAWRENCE KNEISLEY $\ddagger$ \\ From the Department of Neurology, McLean Hospital, ${ }^{*}$ the Harvard Medical School, $\uparrow$ and the \\ Brigham and Women’s Hospital, $\ddagger$ Boston, Massachusetts, USA
}

SUMMARY A 57-year-old woman developed severe generalised amnesia following an embolic stroke. The amnesia persisted until her death nine months later. The left hemisphere had a large infarction of the medial temporal-occipital region, while the right showed only a small infarct limited to the posterior two-thirds of the hippocampus. If bilateral lesions are necessary for the production of permanent amnesia, the findings support the view that the hippocampus is itself a critical structure in the medial temporal diencephalic memory circuit.

Loss of memory may follow brain lesions of limited extent, as demonstrated by vascular lesions, ${ }^{12}$ excisions for epilepsy, ${ }^{3}$ Wernicke-Korsakoff syndrome, ${ }^{4}$ penetrating brain injuries, ${ }^{56}$ or tumours ${ }^{7}$ in the medial temporal lobe and diencephalon. The critical role has generally been attributed to the hippocampus-fornix-mamillary body (HFM) circuits (but of 8). Lesions in the mamillary bodies were related to Korsakoff psychosis in the 19th century; ${ }^{9}$ subsequently lesions of the hippocampus and of the fornix ${ }^{1210-13}$ have been associated with amnesia.

Questions have been raised about the critical role of each part of the circuit. Victor et al concluded that the medial dorsal (MD) nuclei of the thalamus were more important in memory than the mamillary bodies $^{414}$ and CT study of one patient with a traumatic lesion of the left medial dorsal nucleus has supported this view. ${ }^{15}$ There are two problems concerning the critical role of the fornix. First, in a surgical case ${ }^{12}$ bilateral fornix lesions were incidental to the removal of a colloid cyst, during which the walls of the third ventricle may have been damaged, and in a vascular case damage was not limited to the fornices. ${ }^{13}$ Second, there have been cases in which division of the fornices did not result in amnesia. ${ }^{17}$ Finally, the sufficiency of restricted hippocampal lesions in causing lasting amnesia has also been

Presented in part at the 31st Annual Meeting of the American Academy of Neurology, 1979.

Address for reprint requests: Dr Woods, Department of Neurology, McLean Hospital, Belmont, Massachusetts, 02178 , USA.

Received 31 July 1981

Accepted 19 October 1981 questioned. Horel 18 suggested that in cases of amnesia attributed to hippocampal damage, the lesions actually involved the medial temporal lobe and the temporal stem. In monkeys production of amnesia may require damage to the amygdaloid nuclei as well as to the hippocampi. ${ }^{19}$ We have studied a circumscribed bilateral embolic vascular lesion that caused severe generalised amnesia which persisted for the nine months the patient survived. The findings seem relevant to these questions.

\section{Case report}

A 57-year-old alert and well-oriented and uraemic woman was admitted on November 10, 1971 for haemodialysis. A week later her Scribner shunt was found to be clotted and was flushed, producing a good blood flow. A few minutes later the patient was unresponsive. Blood pressure was $130 / 90 \mathrm{~mm} \mathrm{Hg}$ and the pulse was regular. She soon regained consciousness but then was disoriented and unable to remember anything about her admission to hospital. Two days later she was still disoriented to time and place, could not read, but could write, named most colours correctly, but misnamed some objects. Speech was fluent without paraphasic errors. She did not know the name of the President, could not recall any objects after five minutes, and had difficulty remembering the names of her sons. Forward digit span was seven. There was a dense right hemianopia with macular sparing. Tendon reflexes were symmetrical. One week later, she could not recall her age, the date, or her location. She could not read or identify letters or pictures of objects. She made more errors on colour naming.

Two months later she was still so amnesic that it was necessary to pin a note on her lapel telling the taxi driver where to take her when she came for dialysis. Four 
months after onset, she knew she was in a nursing home, but still did not know the date or the name of the President. She remembered six of seven items of a short story after five minutes, but after 15 minutes could not even recall that she had been told the story. Language comprehension and production were intact. Reading and colour naming were done with difficulty but she could identify the meaning of complex pictures and pick out the larger details. When shown pictures of public personalities she was able to name them. Neurological examination showed a dense right upper quadrantanopia, an old Bell's palsy, and slight right sided hyper-reflexia. Five months after onset she remained disoriented to time but now knew the name of her nursing home. When she came to the hospital, it was still necessary to tag information on her coat. She recalled $0 / 3$ objects at five minutes.

Her situation remained essentially the same for the next four months. In early August, 1972, during a shunt revision, she had a cardiac arrest but was resusitated and remained alert. Several days later she had forgotten the whole episode. She complained that her life was "total confusion" because she "forgot things and got lost coming to the hospital." She thought it was May and she was in the nursing home. She suffered a fatal cardiac arrest two weeks later.

Formal intelligence and memory testing were done at two and five months after the stroke (table). Scaled scores for the Wechsler Intelligence ${ }^{20}$ and Memory ${ }^{21}$ tests are shown, along with $\mathrm{Z}$ scores indicating the number of standard deviations by which the patient's scores differed from the age norms supplied with the tests. On the Wechsler memory test the patient did poorly on the information, memory passages, visual reproduction and word associates, but was above average on digit span and mental control. On WAIS, scores were all average or low average except for the digit symbol and object assembly subtests. On the Rey-Osterrieth figures ${ }^{22}$ copying was poor but recall was abysmal. Memory functions appeared to stay stable from the second to the fifth month.

\section{Necropsy report}

The fixed brain weighed 1350 grams. A soft, slightly yellow, well demarcated lesion extended from the posterior inferior temporal surface along the medial lip of the hemisphere to the occipital pole. A small $1.5 \mathrm{~mm}$ lesion was present in the right pons. No other lesions

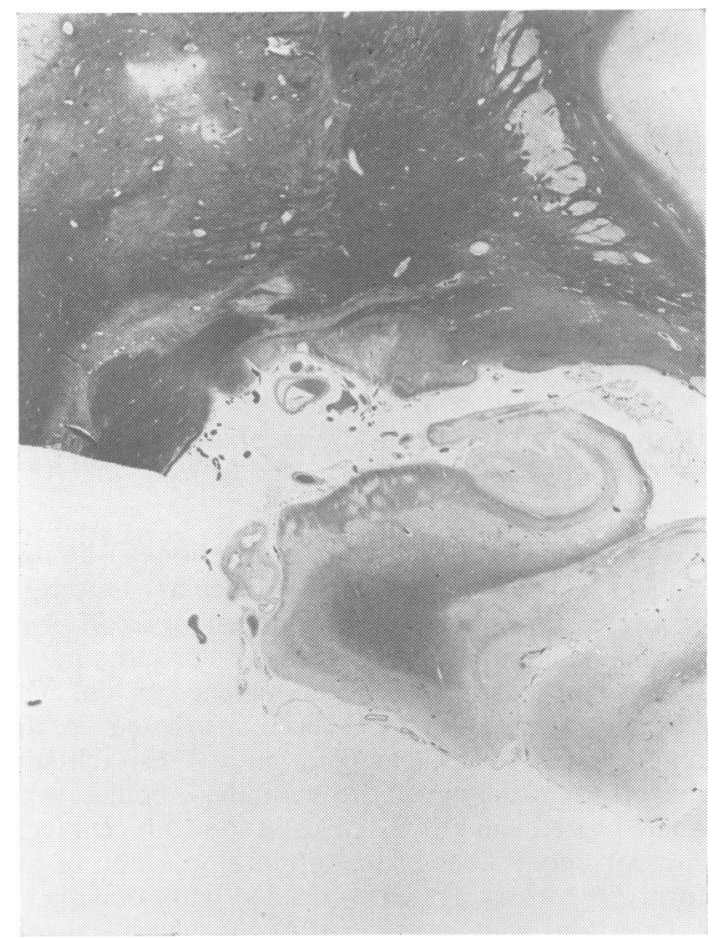

Fig 1 Coronal section at the level of the left lateral geniculate nucleua ( $L G N)$, showing old lesions of hippocampus, hippocampal gyrus, LGN and ventrolateral nucleus of the thalamus.

Table WAIS, WMI and WMII subtest scores and Rey-Osterrieth Figure Scores; Z-scores indicate divergence of the patient's scores from age-standard scores in terms of standard deviations

\begin{tabular}{|c|c|c|c|c|c|c|c|}
\hline \multicolumn{2}{|l|}{$W A I S$} & \multirow{2}{*}{$\frac{Z}{-0.8}$} & \multicolumn{2}{|l|}{$W M I$} & \multirow{2}{*}{$\frac{Z}{-1 \cdot 3}$} & \multirow{2}{*}{$\begin{array}{l}W M I I \\
77\end{array}$} & \multirow{2}{*}{$\frac{Z}{-1 \cdot 5}$} \\
\hline FSIQ & 88 & & MQ & 80 & & & \\
\hline VIQ & 95 & -0.3 & Inf & 3 & $-6 \cdot 8$ & 2 & $-9 \cdot 25$ \\
\hline PIQ & 79 & $-1 \cdot 4$ & Orient & 3 & - & 2 & - \\
\hline Inf & $7^{*}$ & $-1 \cdot 0$ & Ment Con & 8 & +0.7 & 7 & +0.2 \\
\hline Comp & $11^{*}$ & +0.3 & Mem Pass & $3 \cdot 5$ & $-1 \cdot 8$ & $4 \cdot 5$ & -1.4 \\
\hline Arith & 9* & -0.3 & Dig For & 7 & +0.9 & 8 & $+1 \cdot 8$ \\
\hline Sim & $9^{*}$ & $-0 \cdot 3$ & Dig Back & 5 & +0.6 & 5 & +0.6 \\
\hline Dig Sp & $11 *$ & +0.3 & Vis Rep & 1 & $-2 \cdot 3$ & 3 & $-1 \cdot 7$ \\
\hline Voc & $9^{*}$ & -0.3 & Ass Lng & 8 & -1.9 & $4 \cdot 5$ & $-3 \cdot 0$ \\
\hline Dig Sym & $4^{*}$ & $-2 \cdot 0$ & & & & & \\
\hline Pic Comp & $8^{*}$ & -0.7 & \multirow{5}{*}{\multicolumn{2}{|c|}{$\begin{array}{l}\text { Rey-Osterrieth Fig } \\
\text { Copy Score } \\
3 \text { min Recall Score } \\
25 \% \text { ile Copy Score } \\
25 \% \text { ile Recall Score }\end{array}$}} & & $A+2$ months & $A+5$ months \\
\hline BD & $7 *$ & $-1 \cdot 0$ & & & & $21 \frac{1}{2}$ & $18 \frac{1}{2}$ \\
\hline Pict Arr & $7 *$ & $-1 \cdot 0$ & & & & 5 & 0 \\
\hline OA & $3^{*}$ & $-2 \cdot 3$ & & & & & 31 \\
\hline & & & & & & & 18 \\
\hline
\end{tabular}

*Age appropriate scaled score. 


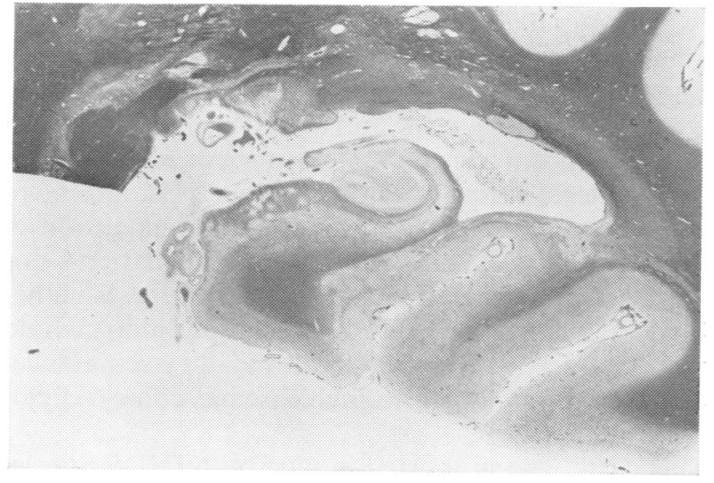

Fig 2 Coronal section at same level as fig 1 showing destruction of white matter underlying the left hippocampal and fusiform gyri as well as demyelination of the optic radiation lateral to $L G N$.

were seen in the brain stem. A single small $2 \mathrm{~mm}$ round, cystic lesion with haemosiderin staining in the walls was present on the inferior surface of the cerebellum. Moderate to severe atherosclerotic changes were present centrally in the major vessels. The circle of Willis was well developed and both posterior communicating arteries were present.

Microscopic examination of the serially sectioned whole brain revealed, in addition to the large lesion on the left seen on gross examination, smaller lesions in the white matter of the left temporal stem, the ventrolateral region of the left thalamus, and the midportion of the lateral geniculate nucleus (fig 1). Anteriorly, the large lesion on the left involved hippocampus, hippocampal gyrus, and the white matter beneath the fusiform (occipito-temporal) gyrus (fig 2). The amygdala was intact. Posteriorly, the lesion undercut the inferior lip of the calcarine fissure and extended inferolaterally to the medial border of the ventricle, destroying lingual and fusiform gyri and the white matter beneath the inferior

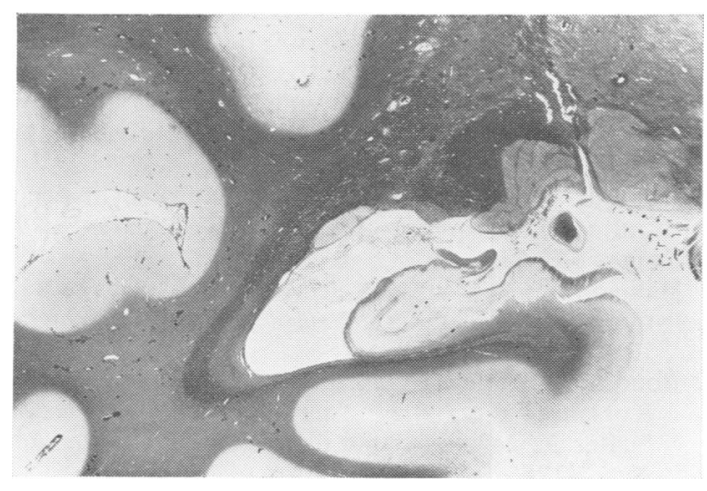

Fig 3 Coronal section at the level of the right $L G N$ showing restricted lesion of the right hippocampus. temporal gyrus, and extending to the occipital pole. The single lesion on the right (fig 3) was limited to the middle and posterior portions of the hippocampus; anteriorly, the lesion began at the level of the anterior lateral geniculate nucleus; posteriorly, it ended just before the termination of the dentate; inferiorly, it involved the subiculum but did not extend beyond the presubiculum into the neocortical portion of the hippocampal gyrus. ${ }^{23}$ The amygdala and temporal stem were uninvolved. The right fornix showed partial demyelination, especially

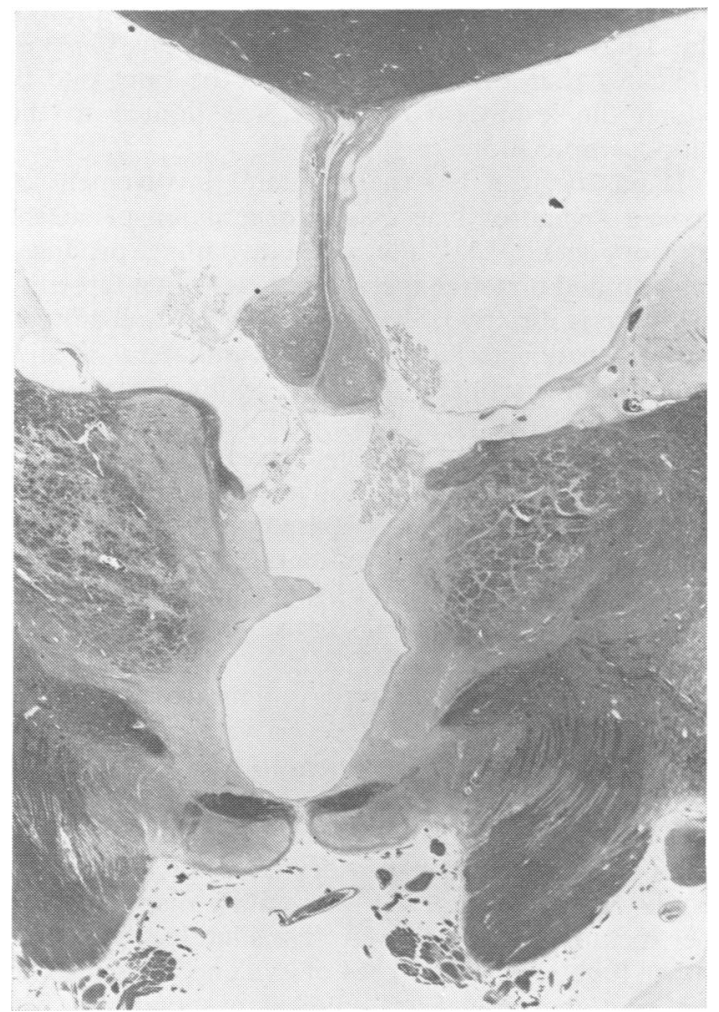

Fig 4 Coronal section at the level of the mammillary bodies showing demyelination of the fornices, more complete on the left.

laterally; that on the left showed more complete demyelination (fig 4).

\section{Discussion}

The study of the anatomy of human memory has depended in large part on scattered clinical cases and has been difficult because of the different types of cases reported and the variety of means of memory assessment employed. Two questions remain incompletely resolved. First, what are the critical 
structures? Second, are bilateral lesions of the critical structures necessary for permanent memory impairment? The two questions are actually related because, if it is held that bilateral lesions are necessary for permanent amnesia, the lesion on each side must include some area critical for memory function. ${ }^{8} 2425$ In the present case, where the right-sided lesion was entirely restricted to the hippocampus, one would conclude that the hippocampus by itself is a critical structure for memory. A review of available published amnesia cases with necropsy verification of the total extent of the bilateral lesions ${ }^{101126-28}$ indicates that the current case is the only one in which the lesion on one side was limited to the hippocampus alone.

It has been stated that bilateral involvement of critical structures is necessary for a major, persistent memory deficit, ${ }^{10}{ }^{13}$ while unilateral damage produces only limited material-specific deficits. ${ }^{29}$ In a sense the evidence is negative; there has been no well-studied pathologically verified case of a unilateral medial temporal-diencephalic lesion with permanent amnesia. Several cases have been reported in which unilateral left-sided lesions have caused severe amnesia, ${ }^{303132}$ but the longest duration of the amnesia was six months..$^{32}$ Based on the evidence to date it is very likely that bilateral lesions are necessary to produce a lasting general amnesia, though left-sided lesions alone may cause severe amnesia for a time.

One specific reservation that might arise about the present case is whether the severity and specificity of the amnesic deficit are sufficient to qualify it as a true amnesia case. The patient's overall Wechsler test scores show no great difference between her Full Scale IQ (88) and her memory quotients $(80,77)$. It could be argued that she was mildly demented and her memory functions were just slightly worse than other functions. Two types of evidence indicate this was not the case. First, clinical observations over many months indicated that she was not diffusely impaired but had two discrete deficits; a severe amnesia and alexia without agraphia. Her amnesia was such that she could not be trusted to tell a taxi driver which hospital to go to and where to return, and it remained devastating until the end of her life. Second, analysis of the subtest scores indicates that on tests of short-term memory (both Wechsler and Rey-Osterrieth) she did poorly, while on tests of rote learning (alphabet, counting backwards) or immediate recall (digit span) she did well. Her very poor performance on the digit symbol subtest of the WAIS, which lowered her performance IQ, can be explained by either her alexia or her memory deficit or both. On all but one of the other subtests of the WAIS she demonstrated normal intelligence.
If bilateral lesions are necessary for generalised amnesia lasting more than six months, ${ }^{23}$ the current case supports the classic view that the hippocampus is a critical structure for human memory. Destruction of the hippocampus alone, when superimposed on a contralateral memory circuit lesion, is sufficient to cause lasting amnesia; neither bilateral extension of the lesion into medial temporal white matter ${ }^{18}$ nor involvement of the amygdala ${ }^{19}$ is necessary. Whether bilateral lesions limited to hippocampus alone would also produce a severe deficit in memory remains an open question. As yet no such case has come to light.

This work was supported in part by NINDS Special Fellowship Grant 2 F11 NS 2370-02 NSRB, National Institutes of Health; in part by Grant RR-88 from the General Clinical Research Center Program of the Division of Research Resources, National Institutes of Health; in part by Grant 72-4-1 from the Alfred P Sloan Foundation; and in part by NIMH Grant NIH-5-RO1-MH24433 to Dr S Corkin. We particularly thank Dr B Murawski of Brigham and Women's Hospital for assistance in the neuropsychological evaluation of the patient.

\section{References}

${ }^{1}$ Bechterew W von. Demonstration eines Gehirns mit Zerstöring der vorderen und inneren Teile der Hirnrinde beider Schläfenlappen. Neurol Zbl 1900; 19:990-1.

2 Glees P, Griffin HB. Bilateral destruction of hippocampus (cornu ammonis) in one case of dementia. Mschr Psychiat Neurol 1952;123:193-204.

${ }^{3}$ Milner B. Memory and the medial temporal regions of the brain. In: Pribram KH, Broadbent DE, eds. Biology of Memory. New York: Academic Press, 1970.

${ }^{4}$ Victor M, Adams RD, Collins G. The WernickeKorsakoff syndrome. In: Plum F, McDowell FH, eds. Contemporary Neurology Series, 7. Philadelphia: FA Davis, 1971.

5 Teuber H-L, Milner B, Vaughn HG. Persistent anterograde amnesia after stab wound of the basal brain. Neuropsychol $1968 ; 6: 278-82$.

6 Jarho L. Korsakoff-like amnesia syndrome in penetrating brain injury. Acta Neurol Scand 1953;29: suppl 54,1-156.

7 Williams M, Pennybacker J. Memory disturbances in third ventricle tumors. J Neurol Neurosurg Psychiatry 1954;17:115-23.

${ }^{8}$ Boudin G, Brion S, Pepin B, Barbizet J. Syndrome de Korsakoff d'étiologie artériopathique, par lésion bilatérale, asymmétrique du systemè limbique. Rev Neurol 1968;119:341-8.

${ }^{9}$ Brierly JB. Neuropathology of amnesic states. In: Whitty CWM, Zangwill OL, eds. Amnesia. London; Butterworths, 1977. 
${ }^{10}$ Penfield W, Milner B. Memory deficit produced by bilateral lesions in the hippocampal zone. Arch Neurol Psychiat 1958;79:475-97.

11 Victor M, Angevine JB, Mancall EL, Fisher CM. Memory loss with lesions of hippocampal formation. Arch Neurol 1961 ;5:244-63.

${ }^{12}$ Sweet WH, Talland GA, Ervin FR. Loss of recent memory following section of the fornix. Trans Am Neurol Assn 1959;84:76-82.

${ }^{13}$ Brion S, Pragier G, Guérin R, Teitgen M. Syndrome de Korsakoff par ramollissement bilatéral du fornix. Rev Neurol 1969;120:255-62.

${ }^{14}$ Adams RD, Collins GH, Victor M. Troubles de la mémoire et de l'apprentissage chez l'homme. Leurs relations avec des lesions due lobes temporaux et du diencephale. Colloques Internationaux du Centre National de la Recherche Scientifique 1962;107:273-95.

${ }^{15}$ Squire L, Moore RY. Dorsal thalamic lesion in a noted case of human memory dysfunction. Ann Neurol 1979;6:503-6.

${ }^{16}$ Mair WGP, Warrington EK, Weiskrantz L. Memory disorder in Korsakoff's psychosis-a neuropathological and neuropsychological investigation of two cases. Brain 1979;102:749-83.

17 Ojemann RG. Correlations between specific human brain lesions and memory changes. Neurosciences Res Prog Bulletin 1966; Vol 4 (suppl).

${ }^{18}$ Horel JA. The neuroanatomy of amnesia. Brain 1978; $101: 403-45$.

${ }^{19}$ Mishkin M. Memory in monkeys severely impaired by combined but not by separate removal of amygdala and hippocampus. Nature 1978;273:297-8.

20 Wechsler D. Manual for the Wechsler Adult Intelligence
Scale. New York: The Psychological Corporation, 1955.

21 Wechsler D. A standardized memory scale for clinical use. J Psychol 1945;19:87-95.

${ }^{22}$ Osterreith P. Le test de copie d'une figure complexe. Arch Psychol 1944;30:306-56.

${ }^{23}$ Truex RC, Carpenter MB. Human Neuroanatomy, 6th ed. Baltimore: The Williams and Wilkins Co, 1969.

${ }^{24}$ Delay J, Brion S, Escourolle R, Marques JM. Demences artériopathiques. Lésions du systeme hippocampomamillo-thalamique dans le déterminisme des troubles mnésiques. Rev Neurol 1961;105:22-33.

${ }^{25}$ Schenk VWD. Unilateral atrophy of the fornix. In: Biemond A, ed. Recent Neurological Research. Princeton, NJ: A van Nostrand Co, Inc., 1959.

${ }^{26}$ DeJong RN, Itabashi HH, Olson JR. Memory loss due to hippocampal lesions. Arch Neurol 1969;20:339-48.

27 Penfield W, Mathieson G. Memory. Arch Neurol 1974; $31: 145-54$.

${ }^{28}$ Van Buren JM, Borke RC. The mesial temporal substrate of memory. Brain 1972;95:599-632.

${ }^{29}$ Milner B. Amnesia following operation on the temporal lobes. In: Whitty CM, Zangwill OL, eds. Amnesia. London: Butterworths, 1966.

${ }^{30}$ Geschwind N, Fusillo M. Color naming deficits in association with alexia. Arch Neurol 1966;15:137-46.

${ }^{31}$ Mohr JP, Leicester J, Stoddard LT, Sidman M. Right hemianopia with memory and color deficits in circumscribed left posterior cerebral artery territory infarction. Neurology (Minneap) 1971;21:1104-13.

${ }^{32}$ Caplan LR, Hedley-White T. Cuing and memory dysfunction in alexia without agraphia. Brain 1974;97: 251-62. 